\title{
A NEW METHODOLOGY FOR WOOD CUTTING OPTIMIZATION IN THE SECONDARY MANUFACTURING PROCESSES.
}

\author{
A.Aguilera ${ }^{1}$, P.J. Méausoone ${ }^{2}$, P. Martin ${ }^{3}$ \\ ${ }^{1}$ Universidad Austral de Chile, Facultad de Ciencias Forestales, Instituto de Tecnología de \\ Productos Forestales, Casilla 567, Valdivia, Chile. Tel : 5663221223 fax : 5663221224 ; e-mail \\ aguilera@uach.cl \\ ${ }^{2}$ Université Henri Poincaré - Nancy I, Ecole Nationale Supérieure des Technologies et Industries \\ du Bois. 27, rue du Merle Blanc - B.P. 1041, 88051 Epinal Cedex 9, France. Tel : 33329811150 \\ fax : 33329340976 ; e-mail meausoone@enstib.u-nancy.fr \\ ${ }^{3}$ Ecole Nationale Supérieure des Arts et Métiers. 4, rue Augustin Fresnel Technopole 2000, 57078 \\ Metz Cedex 3, France. Tel : 33387375430 fax : 33387375470 ; e-mail \\ patrick.martin@metz.ensam.fr
}

\section{Summary}

Cutting conditions determination may help to control design and manufacturing processes. The machining database is important in wood field, that is specific to each tool-machine. So for each kind of wood piece, particular machining conditions are needed to reach a properly surface roughness and a safe work.

Couple Tool Material (COM) method is applied like a new methodology in wood working, centered in secondary wood processing industry, defining the working field of cutting tools taking in mind cutting parameters and limiting the number of experiments.

Working perspectives are wide with the appearance of new cutting materials and high speed cutting processes, so the needs to compute the betters working conditions in wood cutting will be easier with COM data utilization.

\section{Neue Verfahrung für den Schnittoptimizierung in der Holzbearbeitungsprozessen.}

\section{Zusammenfassung}

\section{Introduction}

Wood industry evolution and international competence impose a higher profits, also the apparition of new technologies and cutting materials will be the key points of productivity in the manufacturing process. In an industrial context, wood is a wide utilized material, where process, machines and transformation methods are quite different and specialized depending of wood product to obtain. So each 
machine - tool is associate with a done product, where the interest is to control the machining conditions because very important costs are involved in machines. With optimized cutting conditions, the lost of raw material and the frequency of tool changes are minimized, also the production costs for each piece. In that way the machine profit can be improve.

Restrict cutting conditions in certain limits is associate to type of material to cut, because material determine the cutting behavior. There is very interesting to know the interaction between tool and material, to set a database. All this can identify, for every tool, the acceptable cutting conditions for a specific material. In this way, it can be possible to limiting the working conditions of the tool to maximize the tool life with a right surface roughness of the piece and a safe work. A fundamental problem in wood industry is the misunderstanding of the right cutting conditions for a well-done machining work. In particular in furniture industry with a heterogeneous material.

To determine optimum cutting conditions, metal industry methods are used : the Tool Material Couple COM (AFNOR 1995). Reductions in new production setting time, reduction of industrial delays and costs reasonable are most important advantages of this method. Another advantage for this method is the simple definition for a zone where working tool conditions are fixed according to a series of restrictions to respect. All these restrictions are determined considering machine limits (power), surface roughness or particular conditions (depth of cut).

In wood and wood based materials field, the most important problems are :

- Wood anisotropy behavior with great variations of density. Specimens collected from a same board could have a very different density level.

- Esthetic product aspect is hardly quantified, in a wood surface level; there are some elements like anatomic structures, ring growth, density zones in fiberboard, etc. that shows different quality appreciation.

- Anisotropy, heterogeneity, abrasiveness of wood material are also very important variables that influence results in cutting power, cutting forces and surface roughness.

\section{Wood material problem}

Manufacturing process in wood industry is often oriented according to product defined by the material and his shape. So, a done process is associate to a particular machine. Process is quasi linear and many machines are required. Each one makes a specific operation, depending of machining feature chooses. Moreover, each feature is associated with a specific tool that realizes a specific operation too. The problem is the determination of appropriates cutting conditions for every feature (figure 1). 


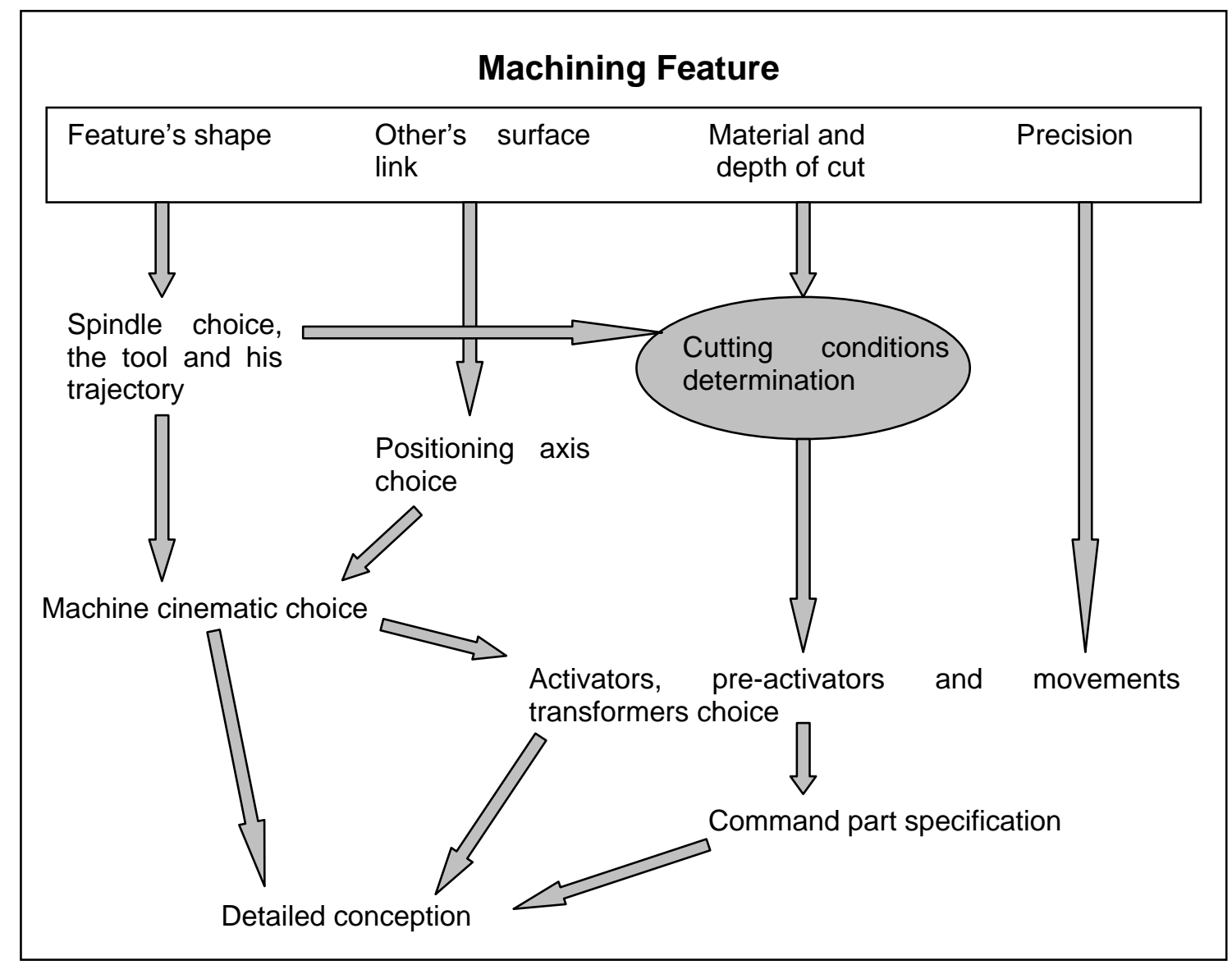

Figure 1 : Cutting conditions determination in a machining feature (Garro 1992). Bild 1 : Bestimmung der Schnittbedingungen.

Cutting conditions are set according to machine and tool limits, with productivity and quality objectives. In wood machining there is no information about the optimum cutting parameters that maximize tool life. To can reach the better cutting conditions Tool Material Couple COM methodology must be employed (Aguilera et al. 2000). This methodology take into account the tool characteristics and material to cut, to optimize cutting conditions, to quantifier tool life and to find a surface quality adequate to the piece use. It can be possible to set a machining database for every machine - tool, and for each concerning material. In this way, operations setting for a machine is minimized and economies are do thanks to an optimal tool work.

Importance of cutting conditions are found it in several levels :

- Breaking tools, caused by a great material size input, bad chip fragmentation, etc.,

- Potentiometers manipulation in CNC machines makes a $20 \%$ of lost in operational time,

- Bad fixed cutting conditions or tool choice, make a lost of 10 to $30 \%$ in tool budgets. 
So, it is possible to consider the following objectives :

- Increase productivity,

- Better quality and regularity in reached qualities,

- Regularity in manufacturing time (non breaking tools, non cutting parameters modification),

- Increase of tool life,

- Avoid machines over - charge.

How can realize the optimization of cutting conditions ?

- If the tool is selected with a done cutting conditions, it must know machine, material and machining characteristics,

- Is selection of cutting conditions are made in function of COM data, it is possible to optimize cutting speed and feed speed in function of quantity of removed material, depth of cut and kerf wide.

\section{COM's approach}

COM's objectives are (AFNOR 1995) in general to permit the choice of the "right tool in a right moment"; and to determine the working field for a tool in a specific material. COM methodology permit to determine this working field by tests, to make an extrapolation with the results of one COM to another, to decrease industrialization time of pieces and to decrease development time for news tools. COM has two objectives : a) it must be simple and fast to obtain and to use; b) it must be accurate to be useful in research and development (Bagur 1996).

COM idea must represent one defined tool that executes a done operation in a defined material under accurate ways. COM is a working point whole. One working point whole is a game of geometric and technologic parameters that respect hygiene and security rules, the art rules, chip formation and adequate tool wear (Levaillant 1996).

The choice of cutting parameters presents some problems like the determination of cutting variables values (feed speed, depth of cut, cutting speed) for every machining operation, limited by tool, machine and piece performances. All these limits generate restrictions on cutting variables determination. In this way it is possible to find the value of cutting variables to belong to the space of realized solutions defined by the restrictions and, optimization level that permit to obtain the optimal values of cutting variables (Lefur et al 1990).

Once COM defined, it can choose a tool in the following way (figure 2) : 


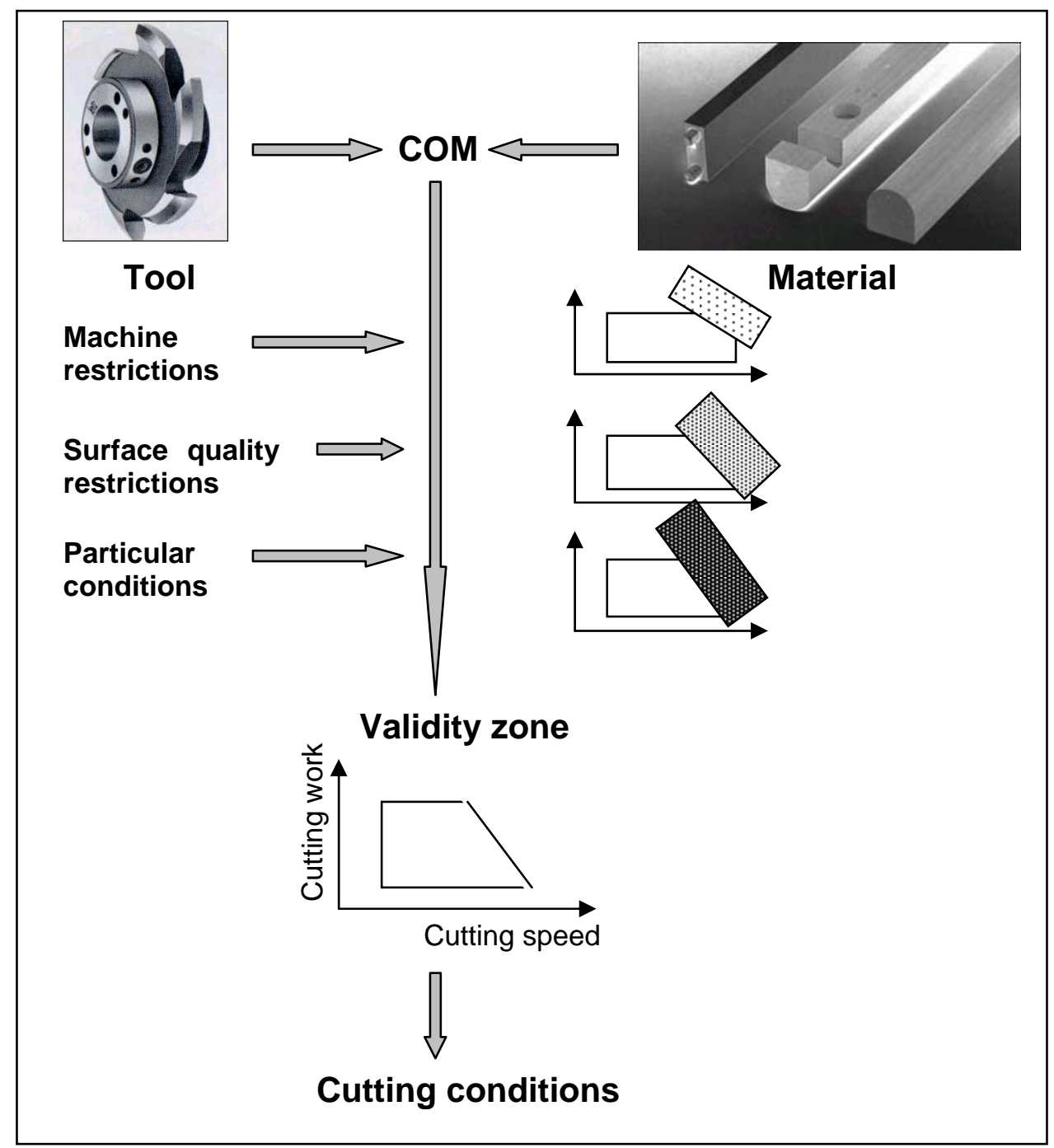

Figure 2 : Tool choice by COM.

Bild 2 : Auswahl der Schnittwerkzeug nach COM.

\section{State of the art}

Optimal cutting conditions determination is researched since many years. Martin (1980) has developed a study in turning operation optimization. The author make emphasis in the fact that the knowledge of restrictions limiting action variables field is important at the time of optimal cutting conditions determination, because the better conditions are situated inside one of them.

These restrictions can be expressed by a straight line in a logarithmic system (figure 3) function of cutting speed $\left(V_{c}\right)$ and bite or advance per tooth $\left(f_{z}\right)$. 


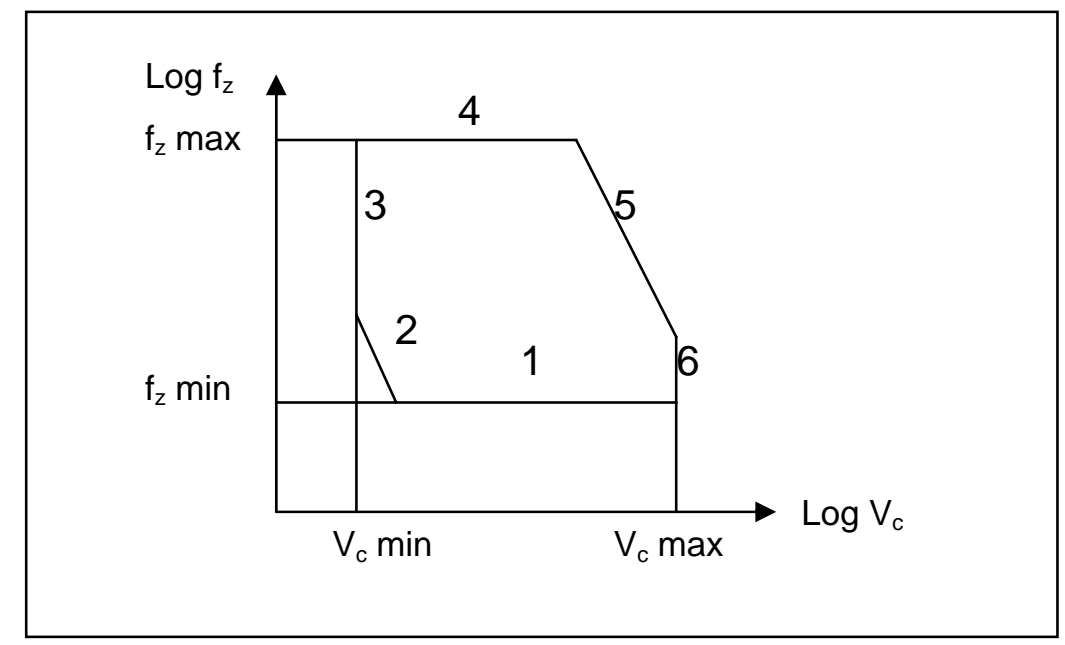

Figure 3 : Restrictions field according to Martin (1980). Bild 3 :

So, the author define restrictions like :

- Restriction $1: f_{z}$ minimum (machine, minimum chip thickness),

- Restriction 2 : limit of tooth point formation,

- Restriction 3 : minimum cutting speed,

- Restriction 4 : maximum $\mathrm{f}_{\mathrm{z}}$, lower limit of restrictions according to maximum advance,

- Restriction 5 : power restriction,

- Restriction 6: maximum cutting speed (machine - tool, tooth point collapse).

The author shows that, in spite of random character for most of these restrictions giving hard their evaluation, it is possible to set a tool working zone (under restrictions) that maximize the tool life.

By other hand, importance of cutting conditions optimization using Tool Material Couple methodology; permit to improve product quality, if surface roughness control is made (Meausoone et al. 2000). Rigal et al. (1996) studied a dynamic model behavior of turning utilizing the COM methodology for experimental verification. The author searched optimal cutting conditions for a smaller system vibration, so, with cutting conditions optimization (chip thickness, depth of cut, bite, cutting speed) the author found stability conditions in turning. Control means was surface roughness analyze in high vibration specimens.

A study carried out by Aguilera (2000), has permit to better understand all functional variables that allow to restrict the working conditions in order to maximize the tool life and achieve the better surface quality. With COM is possible to select the cutting variables that require less cutting energy and discard all disables conditions with a well defined criterion. 
Problems like tool wear behavior can be better studied with COM's methodology. In this sense COM method is very helpful to set optimal cutting conditions in a restricted band, to can reach the point of maximal tool life (Aguilera et al. 1999).

\section{Experimental research}

Not much experimentation has been made in wood cutting optimization, our proposition for the application of a metal methodology in wood operations has like intentions to define which are the parameters to consider, how can be restricted, and what is the better working zone for a tool cutting a specific wood material.

So, the parameters to consider reaching the functional working zone are structured in three types (Aguilera 2000) :

- Cutting limit parameters : that represent maximal and minimal like

$\begin{array}{ll}\text { - } \quad \text { depth of cut } & \text { - bite } \\ \text { - } \quad \text { kerf } & \text { - cutting speed } \\ \text { - chip thickness } & \text { - tool life }\end{array}$

- Link parameters : that link up the maximal between them and the minimal between them. Example, it is not possible to take simultaneously maximal depth of cut and maximal kerf. In this case link parameter is maximal cutting section.

- cutting section

- chip flow

- Auxiliary parameters : that permit in every moment to calculate power, torque and forces generates by machining. These parameters permit to compare the needed energy to cut and the real environmental available energy (Bagur 1996).

- specific cutting energy

- corrector coefficient of the specific cutting energy.

The validity field initially determined will be restricted by the following restrictions :

- surface roughness

- machine - tool characteristics.

And the functionally point used must belong to residual validity field (figure 4) : 


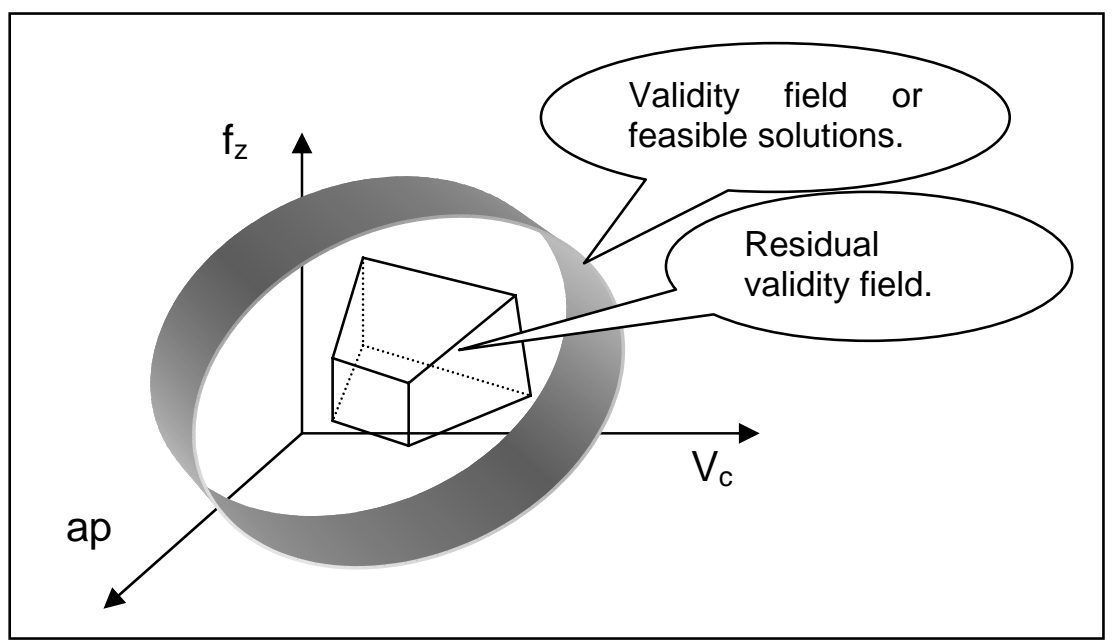

Figure 4 : Residual validity field.

Bild 4 :

\section{Wood results}

Results analyze must consider either cutting power or cutting forces and expressed like specific cutting energy. Another analyze that permit to reinforce these both is the surface roughness, giving the quality standards for a specific cutting condition.

Some schematics results that show the behavior of cutting parameters are shown in the following figures:

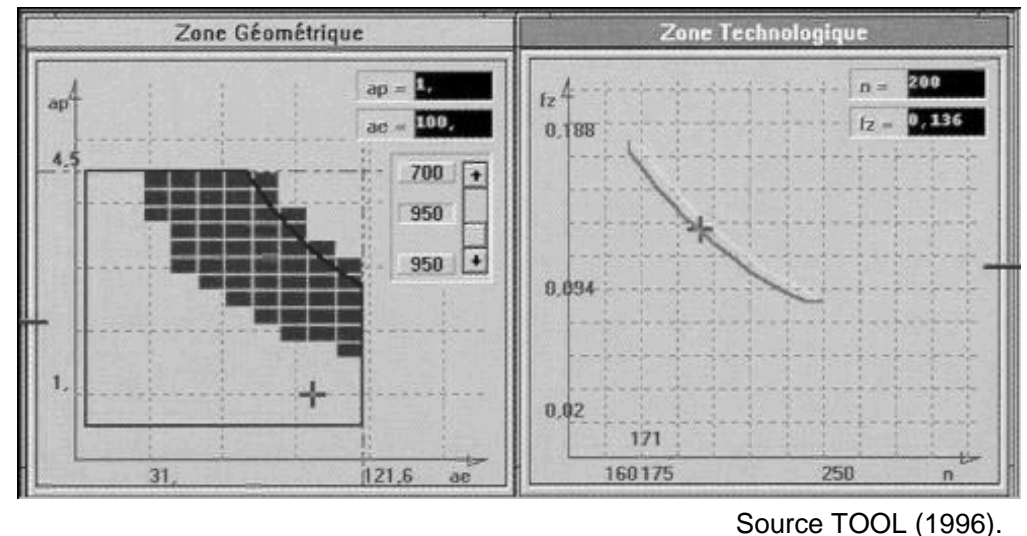

Figure 5 : Geometric and technologic zones in COM's methodology. Bild 5 : Geometrische und technologische Zone nach COM's Methode.

Geometric zone permit to set the utilization track for the maximal and minimal depth of cut and for the maximal and minimal bite. Technological zone sets the tracks for the maximal and minimal cutting speed for a determined tool life. 


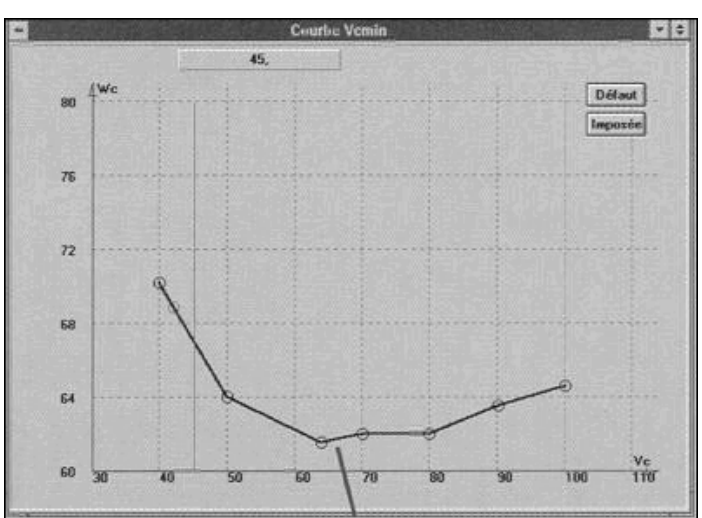

Source TOOL (1996).

Figure 6 : Minimal cutting speed.

Bild 6 : Minimal Schnittgeschwindigkeit.

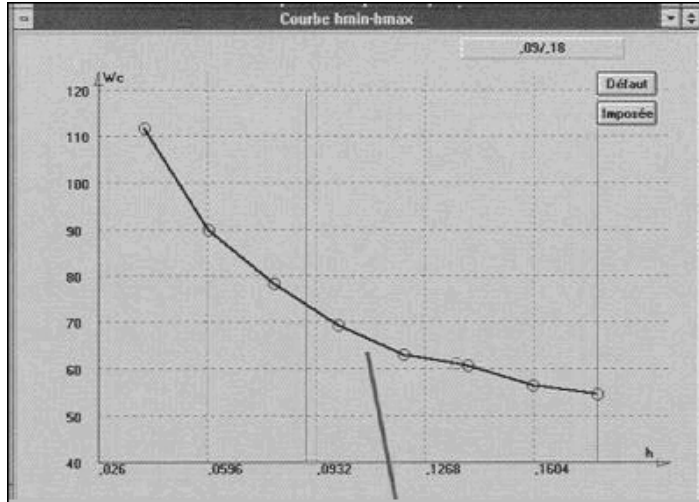

Source TOOL (1996).

Figure 7 : Minimal and maximal chip thickness.

Bild 7 : Minimal und Maximal Spandicke

So minimal cutting speed can be obtained in a point where cutting energy starts to increase. Working with this speed level and all others parameters constants, the chip thickness is gradually reduced to a point where both cutting energy and surface roughness are high. Same operation for maximal chip thickness.

If all characteristics are considered from tool (geometry, diameter), material (species, density, humidity) and machine (rotation speed, feed speed, power), it is possible to know what's are the optimal working zones that permit to maximize the tool life for a well done work expressed like a surface roughness. So, for MDF's material with a small diameter tool with a medium rotation speed, the residual validity zone obtained that's show the feasibility of the application for this methodology is show in the next figure.

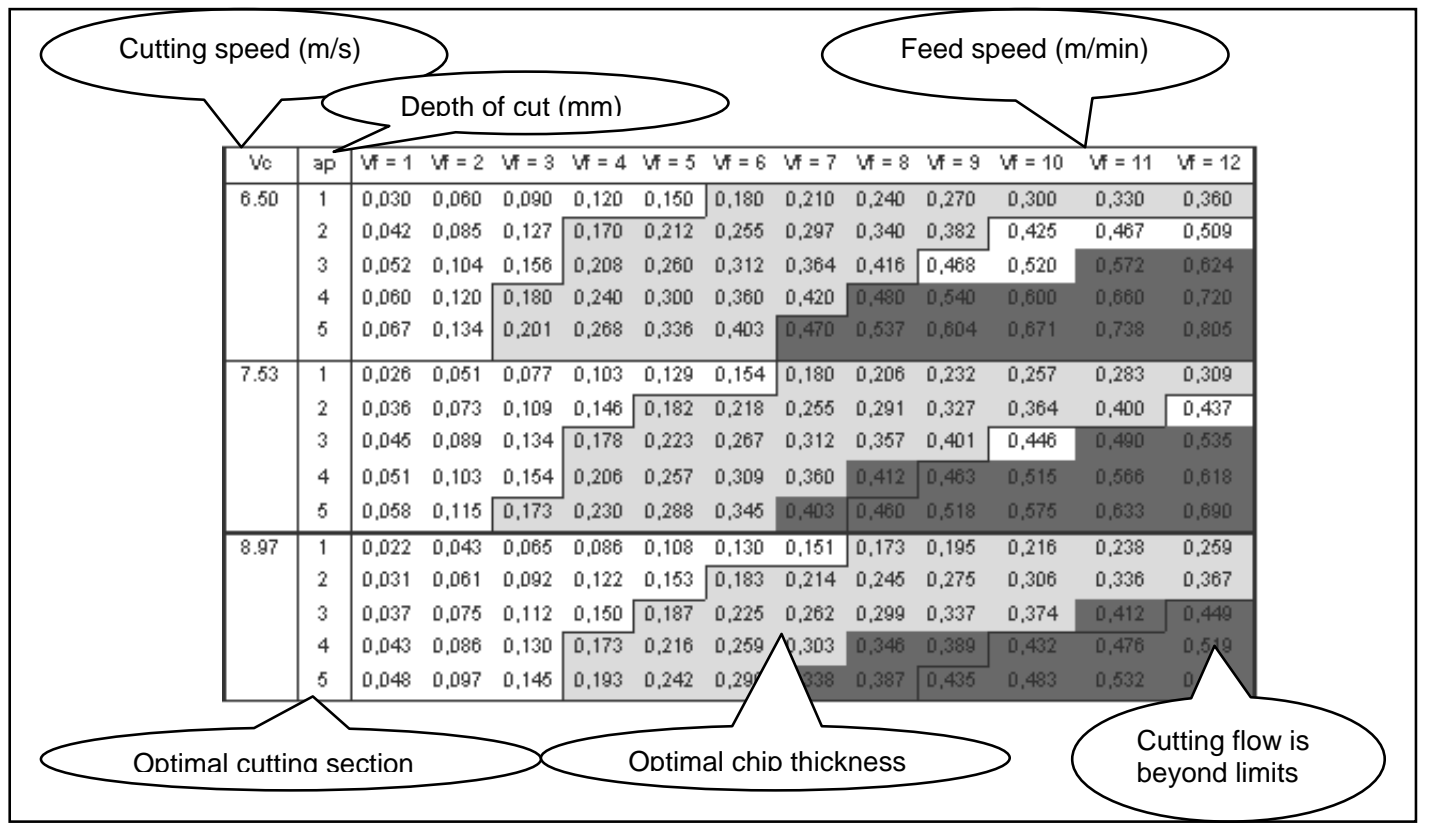

Figure 8 : Residual validity zone; limits for different parameters (Aguilera 2000). Bild 8: 


\section{Conclusions}

The objective of this paper is to show the feasibility of a metal machining methodology application to a wood cutting. This methodology allows fixing cutting conditions limits in order to work in a good cut zone, with right surface roughness and maximizing tool life. In fact, Tool Material Couple methodology permits to choose the tool for machining a done material. This methodology has been used in different metal alloy machining, permitting to researchers to determine the cutting conditions where machining become problematic and so on limiting some cutting parameters in order to reach acceptable surface roughness and minimal tool wear.

In wood machining case, we found that not much research has been done to make a choice for a cutting tool in a specific wood material and to give the limits where the tool can work safely. Wood milling research shows in a subjective manner the surface evaluation since we don't know if cutting conditions are in the right working zone.

Most important advantage for this COM methodology is that permit to make a right choice for a tool that will work in a specific material in considering machine limits, to reach a well done work in terms of surface roughness and safe work. Methodology is normalized and gives fast results with a small quantity of experiments, permitting the creation of a database for a large set of tool and materials.

\section{References}

AFNOR (1995). Domaine de fonctionnement des outils coupants. Couple Outil Matière. Partie 6: mode d'obtention du Couple Outil Matière en fraisage. Indice de classement : E 66-520-6. 57 pp.

Aguilera A. (2000). Optimisation des conditions de coupe pour l'usinage du bois. Application de la méthode du Couple Outil Matière au défonçage des panneaux de fibres de densité moyenne. PhD thesis. Université Henri Poincaré Nancy 1, France. 176 pp.

Aguilera A., Meausoone P.J., Martín P. (1999). Estimation de l'usure en défonçage par la mesure de l'évolution du rapport effort tangentiel / effort normal. 14 th International Wood Machining Seminar, Proceedings - Volume 1, Epinal, France. 19-29.

Aguilera A., Meausoone P.J., Martín P. (2000). Wood material influence in routing operations : the MDF case. Holz als Roh und Werkstoff, 58 (4) 278-283.

Bagur F (1996). Couple Outil Matière : une méthode de conception et de choix des outils de coupe. Colloque International sur l'évolution des matériaux pour outils de coupe, Cercle d'Etudes des Métaux, E.N.S.M. St. Etienne, nov. 1996. 10 pp.

Garro O (1992). Conception d'éléments physiques de système de production: application aux machines outils à architecture parallèle. Thèse Université de Nancy I. 
Lefur E, Mathieu L (1990). Méthodes d'optimisation sous contraintes appliquées à la détermination des conditions de coupe. In: La gamme automatique en usinage, Groupe GAMA. Pages 143-159.

Levaillant $G$ (1996). La prédétermination des conditions et paramètres d'usinage : nécessité, méthodes, moyens. Journée PRIMECA : coupe et usinage, Nantes. Pages 103-110.

Martin P (1980). Commande adaptative de machines-outils. Etude d'un système d'optimisation de l'opération de tournage avec mesure de l'usure de l'outil. Thèse Docteur en Sciences, Université de Nancy I.

Meausoone P.J., Aguilera A., Martín P. (2000). Couple tool material method for cutting conditions : A new approach of optimisation. First International Symposium on wood machining, September 27-29, Vienna, Austria. 105-116.

Rigal JF, Mehdi K (1996). Modèles dynamiques du comportement des tubes minces en tournage. Journée PRIMECA : coupe et usinage, Nantes. Pages 17-22.

Société TOOL (1996). Le Couple Outil Matière. Usinage par outils coupants. Société TOOL, Annecy. 11 pp. 